\title{
Study Sponsor Monitor
}

National Cancer Institute

\section{Source}

National Cancer Institute. Study Sponsor Monitor. NCI Thesaurus. Code C90463.

An entity that is responsible for overseeing the activities of the study sponsor. 